\title{
Uniconazole confers chilling stress tolerance in soybean (Glycine max L.) by modulating photosynthesis, photoinhibition, and activating oxygen metabolism system
}

\author{
J.J. ZHAO*, N.F. FENG ${ }^{*,+}$, X.X. WANG ${ }^{*}$, G.R. CAI*, M.Y. CAO*, D.F. ZHENG ${ }^{*, *,+}$, and H.D. ZHU, ${ }^{*,+}$
}

Heilongjiang Bayi Agricultural University, Daqing, Heilongjiang 163000, China*

National Coarse Cereals Engineering Research Center, Daqing, Heilongjiang 163000, China**

\begin{abstract}
The current study investigates a possible mediatory role of uniconazole in improving chilling stress tolerance in chillingsensitive (Hefeng 50) and chilling-tolerant (Kenfeng 16) soybean varieties. Chilling stress decreased photosynthetic pigments and inhibited net photosynthetic rate which was ascribed to stomatal limitation. The maximum quantum efficiency of PSII primary photochemistry and electron transport rate were lower in uniconazole-treated plants compared with the control. The increased contents of superoxide $\left(\mathrm{O}_{2}{ }^{-}\right)$and malondialdehyde during chilling stress indicated oxidative stress. Chilling stress reduced glutathione and ascorbic acid contents, and promoted peroxidase, glutathione reductase, and ascorbate peroxidase activities. Uniconazole improved the tolerance of chilled plants. This might be due to better antioxidant defense mechanisms including higher contents of antioxidants and activities of antioxidant enzymes, which retard lipid peroxidation. Thus, uniconazole has a positive effect and improves the chilling resistance of soybean.
\end{abstract}

Additional key words: carotenoid; catalase; chlorophyll; reactive oxygen species; superoxide dismutase.

\section{Introduction}

Chilling stress is one of the destructive abiotic stresses that restricts photosynthesis and eventually limits agricultural production and quality of tropical and subtropical plants (Allen and Ort 2001, Ikeda et al. 2009, Liu et al. 2012, Nahar et al. 2015). Reduction in electron transport (Zhao et al. 2016) and photosynthetic efficiency, and changes in protein structure and enzyme activities are some of the most common and primary chilling injury symptoms within plants. Inhibition of the carbon reduction cycle (Allen and Ort 2001), PSII activity (Strauss et al. 2006), and photosynthesis (Savitch et al. 1997, Allen and Ort 2001) under chilling stress increases generation of reactive oxygen species (ROS) (Gill and Tuteja 2010, Zhao et al. 2016). To overcome such conditions and neutralize or counteract the deleterious effects of ROS and protect plants from oxidation damage, the antioxidant defense system with different antioxidant components maintains a delicate balance between ROS generation and scavenging (Nahar et al. 2015). The antioxidant defense system consists of nonenzymatic antioxidants, such as glutathione (GSH), ascorbic acid (AsA), and enzymatic antioxidants, such as superoxide dismutase (SOD), catalase (CAT), ascorbate peroxidase (APX), monodehydroascorbate reductase (MDHAR), dehydroascorbate reductase (DHAR), glutathione reductase (GR), and peroxidase (POD). These enzymes scavenge ROS with AsA and GSH as electron acceptors (Gill and Tuteja 2010, Liu et al. 2015, Nahar et al.2015). Various strategies are being employed to alleviate the adverse effects of chilling stress in plants. Foliage spray of plant growth regulators (PGRs) is an effective, facile, and practical technique to enhance tolerance of plants, which has been used widely in recent years (Zhang et al. 2007, Manafi et al. 2015, Zhao et al. 2016).

$S$-(+)-uniconazole has been used as a plant growth retardant, inhibiting biosynthesis of gibberellins (GA) and abscisic acid (ABA) (Saito et al. 2006), and for

\footnotetext{
Received 4 January 2018, accepted 15 October 2018.

+Corresponding authors; phone:+86 18345993708, e-mail: byndfnj@126.com. byndzdf@126.com, zhdbyndkys@sohu.cn

Abbreviations: ABA - abscisic acid; APX - ascorbate peroxidase; AsA - reduced ascorbic acid; Car - carotenoids; CAT - catalase; Chl - chlorophyll; $C_{\mathrm{i}}$ - intercellular $\mathrm{CO}_{2}$ concentration; DAB - 3,3-diaminobenzidine; DHA - oxidized ascorbic acid; DHAR dehydroascorbate reductase; $E$ - transpiration rate; ETR - electron transport rate; FM - fresh mass; $\mathrm{F}_{\mathrm{v}} / \mathrm{F}_{0}-$ size and number of active reaction centers; $F_{v} / F_{m}$ - maximum photochemical efficiency of PSII; GA - gibberellins; GR - glutathione reductase; $g_{\mathrm{s}}$ - stomatal conductance; GSH - reduced glutathione; GSSG - oxidized glutathione; MDA - malondialdehyde; MDHAR - monodehydroascorbate reductase; NBT - nitroblue tetrazolium chloride; PGRs - plant growth regulators; $P_{\mathrm{N}}$ - net photosynthetic rate; POD - peroxidase; ROS - reactive oxygen species; SOD - superoxide dismutase.

Acknowledgements: The research was financially supported by National Natural Science Foundation of China (31571613), National Natural Science Foundation of China (31871576) and Heilongjiang Outstanding Youth Fund (JC201309).
} 
enhancement of plant tolerance to environmental stresses (Todoroki et al. 2009), such as water deficit (Zhang et al. 2007, Duan et al. 2008), heat (Wan and Kothare 1999), waterlogging (Qiu et al. 2005), chilling (Chucheep et al. 2005), metal (He et al. 2017), and salt stress (Al-Rumaih and Al-Rumaih 2015). All these stresses lead to a decline of the net photosynthetic rate $\left(P_{\mathrm{N}}\right)$ and to increases in ROS contents. Recent studies have identified that uniconazole possessed antioxidant activity modulated by augmenting contents of antioxidants and stimulating antioxidant enzymes to scavenge excess ROS (Wan and Kothare 1999, Qiu et al. 2005, Zhang et al. 2007). Moreover, in soybean, uniconazole pretreatment can effectively suppress excessive vegetative growth during the flowering stage, delay senescence of leaves at pod-setting stage, and improve final yields (Yan et al. 2015).

Soybean (Glycine $\max$ L.) is native to subtropical regions and is regarded as chilling-sensitive species. When temperature drops below $20^{\circ} \mathrm{C}$, its growth and development significantly retards (Balestrasse et al. 2010). Due to expansion of soybean growing areas toward cooler climates, the whole growth and development of soybean is exposed to chilling stress (Balestrasse et al. 2010). Therefore, the tolerance to chilling stress at the beginning of the flowering stage is one of the important challenges under a cold climate. Several studies exist on soybean chilling-stress tolerance in the seedling (Balestrasse et al. 2010, Tian et al. 2015), flowering (Ohnishi et al. 2010), pod-formation (Takahashi et al. 2005), and seed-filling stages (Funatsuki et al. 2004, Ikeda et al. 2009). Ohnishi et al. (2010) reported decreased pollen grain number on stigma, suggesting that insufficient pollination leads to low pod setting. Hall (2000) and Singh et al. (2010) showed that the response of vegetative growth is more sensitive than reproductive growth under chilling stress. Photosynthesis is the major determinant of a pod and seed number (Egli 2005). To ensure stable production of soybean under temperate climates, a greater understanding of chilling stress effects is required, especially at the flowering stage.

There are few studies in soybean leaves concerning the effect of uniconazole on the photosynthesis, photoinhibition, and the balance of ROS generated under chilling stress, especially at the beginning of the flowering stage. Therefore, the present investigation was conducted to determine whether uniconazole confers chilling tolerance to soybean plants and if such tolerance is correlated with changes in photosynthesis, photoinhibition, and oxygen metabolism.

\section{Materials and methods}

Plant material, growth conditions, and chilling-stress treatment: The experiment was conducted at Heilongjiang Academy of Agricultural Sciences located in Northeast China $\left(34^{\circ} 30^{\prime} \mathrm{N}, 119^{\circ} 32^{\prime} \mathrm{E}\right)$ from May to October 2017. The seeds of popular soybean varieties, Kenfeng 16 and Hefeng 50, were sown at a rate of ten seeds per plastic pot (lower inside diameter of $20.0 \mathrm{~cm}$, upper inner diameter of $28.0 \mathrm{~cm}$, and height of $23.0 \mathrm{~cm}$ ) filled with premixed air-dried soil [150.0 $\mathrm{g}\left(\mathrm{NH}_{4}\right)_{2} \cdot \mathrm{SO}_{4}, 130.0 \mathrm{~g} \mathrm{~K}_{2} \mathrm{SO}_{4}$, and
$50 \mathrm{~g}\left(\mathrm{NH}_{4}\right)_{2} \mathrm{HPO}_{4}$ per pot], and no additional fertilization. Subsequently, five seedlings were retained after thinning at the second trifoliate leaf stage (V2 growth stage). All pots were placed on greenhouse benches under the natural environment. Standard practices suiting pot experiments were followed, and no pest or disease problems were found during the experimental period. At the beginning of the flowering stage (R1), one third of the plants (60 plants) were sprayed with $50 \mathrm{mg} \mathrm{L}^{-1}$ uniconazole solution (Zhang et al. 2007) and the rest (120 plants) were sprayed with distilled water. About $36 \mathrm{~h}$ after uniconazole spray, 60 of uniconazole-treated and 60 of water-sprayed plants were placed in a growth chamber under low temperature conditions $\left[15 / 15^{\circ} \mathrm{C}-\right.$ day/night temperature, relative humidity (RH) of $75 \%$, and a natural light photoperiod] (Funatsuki et al. 2004, Ikeda et al. 2009). The remaining water-treated plants were placed under natural environments as controls. This experiment was set up in a completely randomized design with four replications. Fully expanded third trifoliate leaves were sampled from the main apex of each treatment on 1, 2, 3, and $4 \mathrm{~d}$ after spraying. The collected samples were allowed to recover for $1,2,3$, and $4 \mathrm{~d}$, then frozen in liquid nitrogen, and stored at $-80^{\circ} \mathrm{C}$ until physiological and biochemical analyses were done.

Chlorophyll (Chl) content: Photosynthetic pigments, such as Chl $a, \mathrm{Chl} b, \mathrm{Chl}(a+b)$, and carotenoids (Car), were determined following the method described by Arnon (1949) with a minor modification. Fresh leaf tissue $(100 \mathrm{mg})$ was soaked in $10 \mathrm{~mL}$ of absolute ethanol until the pellets became colorless. The optical density of the solution was measured spectrophotometrically at 663, 645, and $470 \mathrm{~nm}$ (UV-3600 Plus, Shimadzu, Japan).

Gas-exchange parameters: Net photosynthetic rate $\left(P_{\mathrm{N}}\right)$, transpiration rate $(E)$, intercellular $\mathrm{CO}_{2}$ concentration $\left(C_{\mathrm{i}}\right)$, and stomatal conductance $\left(g_{\mathrm{s}}\right)$ were measured on the third fully expanded trifoliate leaves from the main apex using a portable photosynthesis system ( $\mathrm{Li}$-Cor 6400, Li-Cor Inc., Nebraska, USA). Plants were measured under PPFD of $1,000 \mu \mathrm{mol}$ (photon) $\mathrm{m}^{-2} \mathrm{~s}^{-1}, \mathrm{CO}_{2}$ concentration of 500 $\mu \mathrm{mol} \mathrm{mol}{ }^{-1}, 25 \pm 3^{\circ} \mathrm{C}$, and $80 \%$ humidity.

Chl $\boldsymbol{a}$ fluorescence parameters: Maximum quantum efficiency of PSII primary photochemistry of dark-adapted plants $\left(\mathrm{F}_{\mathrm{v}} / \mathrm{F}_{\mathrm{m}}\right)$, size and number of active reaction centers of PSII $\left(\mathrm{F}_{\mathrm{v}} / \mathrm{F}_{0}\right)$, and electron transport rate $(\mathrm{ETR})$ were measured by a modulated Chl fluorescence spectrometer system (OS5p, OPTI-Sciences, USA) on control and chilling-stress-treated fully expanded leaves that were used for fluorescence measurements.

Histochemical detection of hydrogen peroxide and superoxide anion: Sampling for histochemical detection analysis was carried out $4 \mathrm{~d}$ after low temperature treatment. Accumulation of hydrogen peroxide $\left(\mathrm{H}_{2} \mathrm{O}_{2}\right)$ and superoxide anion $\left(\mathrm{O}_{2}{ }^{-}\right)$were localized histochemically by staining with $1 \%$ 3,3-diaminobenzidine (DAB) and $0.1 \%$ nitroblue tetrazolium chloride (NBT) solution following 
the method of Chen et al. (2010) and Wei et al. (2015), respectively. After soaking for $6 \mathrm{~h}$, the dyed leaves were immersed in $50 \mathrm{~mL}$ of mixed solution of absolute ethanol and glacial acetic acid $(3: 1, \mathrm{v} / \mathrm{v})$ and placed in a hot water bath for $30 \mathrm{~min}$. Photos were taken when the leaves turned colorless.

Superoxide anion and lipid peroxidation: Leaves were homogenized in a K-P buffer solution ( $\mathrm{pH}$ 7.8) and centrifuged at $5,000 \times g$ to monitor the formation of nitrite from hydroxylamine, following Wang and Luo (1990). Supernatant was mixed with extraction buffer and hydroxylamine hydrochloride. After $20 \mathrm{~min}$ of incubation, sulfanilamide and naphthylamine were added. The production rate of superoxide anion was measured spectrophotometrically at $530 \mathrm{~nm}(U V-3600$ Plus, Shimadzu, Japan) and expressed as $\mathrm{nM}\left(\mathrm{O}_{2}{ }^{--}\right) \min ^{-1} \mathrm{~g}^{-1}$ (protein).

The level of lipid peroxidation in leaves was measured by the thiobarbituric acid (TBA) test with modifications from Dhindsa et al. (1981) and Liu et al. (2015). TBA test determined content of malondialdehyde (MDA), an end product of lipid peroxidation. Leaf samples of $0.1 \mathrm{~g}$ were homogenized in $5 \mathrm{~mL}$ of $0.05 \mathrm{M}$ phosphate buffer, $\mathrm{pH} 7.8$, and then centrifuged at $12,000 \times g$ for $20 \mathrm{~min}$. Supernatant ( $1 \mathrm{~mL}$ ), $1 \mathrm{~mL}$ of PBS buffer ( $\mathrm{pH} 7.8$ ), and $2 \mathrm{~mL}$ of $0.5 \%$ TBA were incubated in boiling water for $15 \mathrm{~min}$. Then the mixture returned to room temperature and was centrifuged at $1,800 \times g$ for $10 \mathrm{~min}$. Samples were measured using a spectrophotometer (UV-3600 Plus, Shimadzu, Japan) at 532 and $600 \mathrm{~nm}$. The MDA content was calculated using the extinction coefficient of $155 \mathrm{mM}^{-1} \mathrm{~cm}^{-1}$.

Extraction and measurement of ascorbate and glutathione: The content of nonenzymatic antioxidants, such as reduced (AsA) and oxidized (DHA) ascorbate, was determined following the method given by Zhang and Kirkham (1996). The supernatant was extracted with 5\% phosphoric acid, and centrifuged at $22,000 \times g$ for $15 \mathrm{~min}$ at $4^{\circ} \mathrm{C}$. The supernatant was collected and used for the analysis of AsA and DHA content according to Nahar et al. (2016). The mixture contained $0.5 \mathrm{~mL}$ of enzyme extract, $1.5 \mathrm{~mL}$ of $5 \%$ phosphoric acid, $1.0 \mathrm{~mL}$ of absolute ethanol, $0.5 \mathrm{~mL}$ of $0.4 \% \mathrm{H}_{3} \mathrm{PO}_{4}$-ethanol, $1.0 \mathrm{~mL}$ of $0.5 \%$ 4,7-diphenyl-1,10-phenanthroline-ethanol, and $0.5 \mathrm{~mL}$ of $0.03 \% \mathrm{FeCl}_{3}$-ethanol, and then was placed under a constant temperature to a water bath at $30^{\circ} \mathrm{C}$ for $90 \mathrm{~min}$. Samples were measured using a spectrophotometer (UV-3600 Plus, Shimadzu, Japan) at $525 \mathrm{~nm}$.

The supernatant was used for assays of reduced (GSH) and oxidized glutathione (GSSG) contents, following the method described by Grace and Logan (1996). A 0.1-g leaf sample was homogenized in $5 \mathrm{~mL}$ of $5 \mu \mathrm{mol}(\mathrm{EDTA}-$ TCA) $\mathrm{L}^{-1}$ and centrifuged at $11,500 \times \mathrm{g} \mathrm{min}^{-1}$ for $15 \mathrm{~min}$. The reaction mixture consisted of $1.0 \mathrm{~mol}(\mathrm{NaOH}) \mathrm{mL}^{-1}$, dithionitrobenzoic acid (DTNB), and the enzyme extract. The reaction was initiated by the addition of 0.2 unit of glutathione reductase (GR) (from yeast, Boehringer Mannheim) in a total volume of $2 \mathrm{~mL}$. Samples were measured using a spectrophotometer (UV-3600 Plus, Shimadzu, Japan) at $412 \mathrm{~nm}$.
Antioxidant enzyme extraction and assays: Using a precooled mortar and pestle, soybean leaves $(0.5 \mathrm{~g})$ were homogenized in $10 \mathrm{~mL}$ of $50 \mathrm{mM}$ ice cold PBS buffer $\left(\mathrm{pH} \mathrm{7.0)}\right.$ and centrifuged at $11,500 \times \mathrm{g}$ for $15 \mathrm{~min}$ at $4^{\circ} \mathrm{C}$. The supernatant was used for enzyme activity assay.

The activity of ascorbate peroxidase (APX, EC 1.11.1.11) was measured following the method of Cakmak and Marschner (1992). The reaction mixture contained 100 mM H $\mathrm{O}_{2}, 50 \mathrm{mM}$ PBS ( $\mathrm{pH} 7.0$ ), $15 \mathrm{mM}$ AsA, $0.1 \mathrm{mM}$ EDTA, and enzyme extract. The activity was measured by observing the decrease in absorbance at $290 \mathrm{~nm}$ (UV-3600 Plus, Shimadzu, Japan) for 1 min using an extinction coefficient of $2.8 \mathrm{mM}^{-1} \mathrm{~cm}^{-1}$.

Catalase (CAT, EC 1.11.1.6) activity assessment was made according to the method of Fu and Huang (2001) by monitoring the change of absorbance (by decomposition of $\left.\mathrm{H}_{2} \mathrm{O}_{2}\right)$ and recording its value at $240 \mathrm{~nm}(U \mathrm{~V}-3600$ Plus, Shimadzu, Japan) for $1 \mathrm{~min}$. The activity was calculated using the extinction coefficient of $39.4 \mathrm{M}^{-1} \mathrm{~cm}^{-1}$.

The activity of glutathione reductase (GR, EC 1.6.4.2) was determined according to Esterbauer and Grill (1978) based on the rate of NADPH oxidation at $340 \mathrm{~nm}$. The reaction mixture consisted of $0.3 \mathrm{~mL}$ of $20 \mathrm{mM}$ disodium ethylenediaminetetraacetate (EDTA-Na $), 0.4 \mathrm{~mL}$ of $5 \mathrm{mM}$ oxidized glutathione (GSSG), and $1.1 \mathrm{~mL}$ of $50 \mathrm{mmol} \mathrm{L}^{-1}$ (pH 7.8) PBS buffer, and placed in a water bath at $25^{\circ} \mathrm{C}$ for $5 \mathrm{~min}$. Reaction was initiated with $0.2 \mathrm{~mL}$ of $10 \mathrm{mmol} \mathrm{L}^{-1}$ NADPH and decrease in absorbance at $340 \mathrm{~nm}(U V-3600$ Plus, Shimadzu, Japan) was recorded for 1 min (extinction coefficient of $\left.6.2 \mathrm{mM}^{-1} \mathrm{~cm}^{-1}\right)$.

Peroxidase (POD, EC 1.11.1.7) activity was determined by the method of Polle et al. (1994). One unit of POD was defined as the amount of enzyme that oxidated guaiacol at $470 \mathrm{~nm}$ (UV-3600 Plus, Shimadzu, Japan) upon incubation at $30^{\circ} \mathrm{C}$ during the linear phase of the reaction. The activity of POD was expressed as $\mu$ mol(product) $\mathrm{min}^{-1} \mathrm{~g}^{-1}(\mathrm{FM})$. For the POD assay, a $3.0 \mathrm{~mL}$ reaction mixture contained $20 \mathrm{mmol} \mathrm{L}^{-1}$ guaiacol and $0.1 \mathrm{M} \mathrm{H}_{2} \mathrm{O}_{2}$ in $50 \mathrm{mmol} \mathrm{L}^{-1}$ (pH 7.8) PBS buffer. The reaction was initiated by adding $0.2 \mathrm{~mL}$ crude enzyme preparations.

Statistical analysis: The differences between treatment and control are presented in figures and tables and were performed on four replicates. All data were subjected to analysis of variance $(A N O V A)$ and Duncan's multiple range test at $P<0.05$ significance level between treatment and control with SPSS (21.0) software. The figures were drawn by OriginPro 9.1 software (OriginLab, Northampton, MA, USA).

\section{Results}

Photosynthetic pigments: The Chl content is an important index to assess the damage caused by stress factors for photosynthetic organs (Erdal 2012). Chl $a, \mathrm{Chl} b, \mathrm{Chl}(a+b)$, and Car contents in both soybean varieties declined with the prolongation of the low temperature treatment when compared to their controls (Fig. 1). However, the decline in Chl $a$, Chl $b$, Chl $(a+b)$, and Car content was lower in chilling-sensitive Hefeng 50 as compared to chilling- 


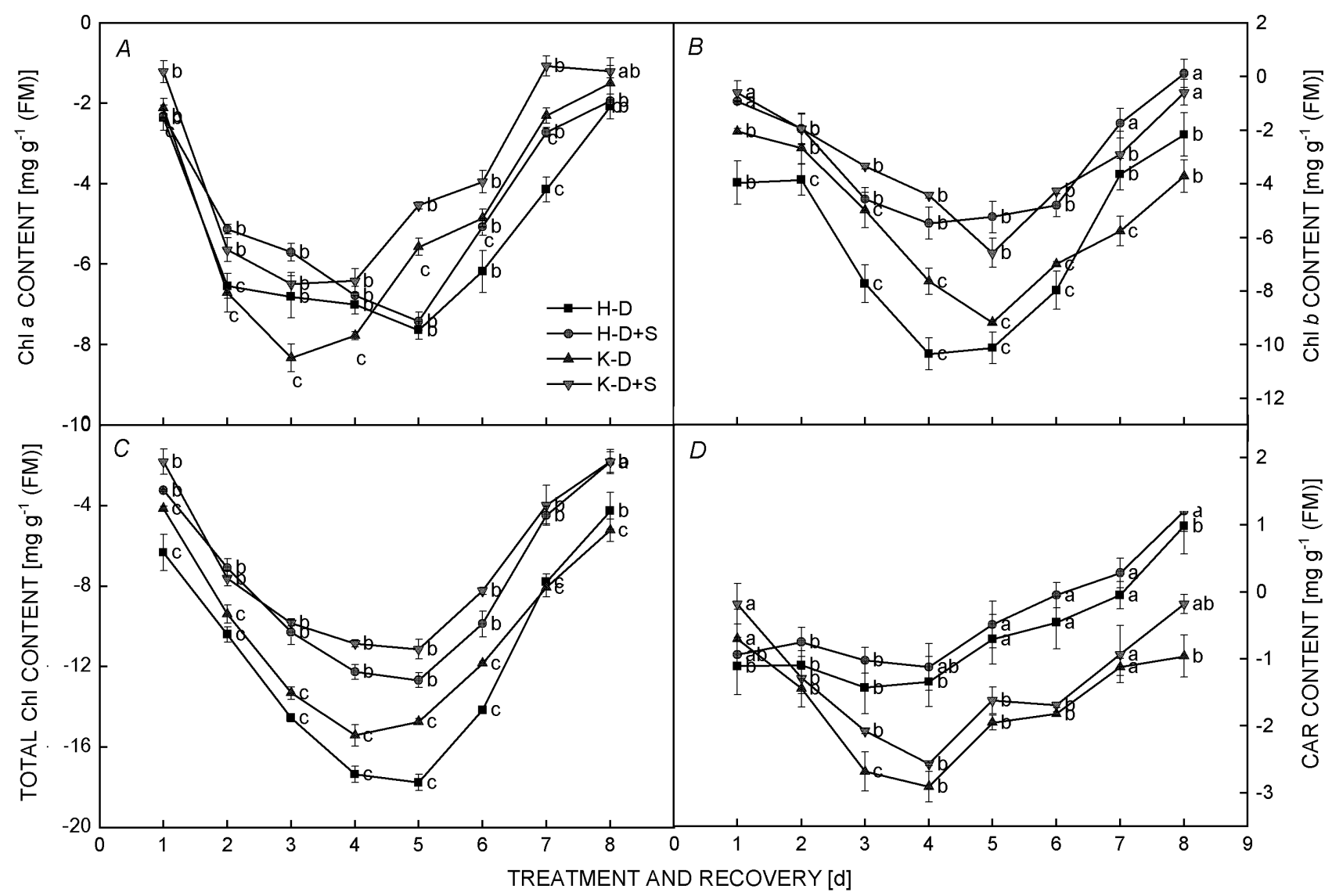

Fig. 1. Effect of uniconazole on chlorophyll $a(A)$, chlorophyll $b(B)$, chlorophyll $(a+b)(C)$, and carotenoid $(D)$ contents in soybean leaves. From day 1 to day 4 , the plants were under chilling stress, and from day 5 to day 8 , the plants returned to their natural environment (recovery period). Data (means $\pm \mathrm{SE}, n=4$ ) are the difference between treatments. Different letters above horizontal lines indicate significant differences between treatments. D - chilling stress, D + S - chilling stress + uniconazole, H - Hefeng 50, K - Kenfeng 16.

tolerant Kenfeng 16. From day 1 to day 4, the above indicators decreased by $9.5-28.0,22.6-65.9,14.9-42.6$, and $44.3-56.0 \%$, respectively, in Hefeng 50 , while they decreased by $7.0-26.8,12.4-52.4,8.9-35.3$, and $36.4-$ $49.5 \%$, respectively, in Kenfeng 16 . It is worth noting that the degradation rate of Chl $a$ was slower than that of $\mathrm{Chl} b$. The application of uniconazole effectively relieved the degradation of the above contents in chilling-stressed plants.

Chl $a$, Chl $b$, Chl $(a+b)$, and Car contents in soybean leaves gradually increased with the prolongation of recovery time (from day 5 to day 8), and the increasing Chl content was significantly promoted by uniconazole treatment (Fig. 1). Altogether, uniconazole treatment in chilling-stressed plants alleviated the toxic effect on Chl but the above contents were lesser than that of control during chilling stress and recovery periods.

Photosynthesis: The decline of $P_{\mathrm{N}}$ was accompanied by a reduction in $g_{\mathrm{s}}$ and $E$, which increased $C_{\mathrm{i}}$ under chilling stress (Fig. 2). Protective effects of uniconazole were reflected by reduction of photosynthesis parameters, such as $P_{\mathrm{N}}, g_{\mathrm{s}}$, and $E$. In Hefeng 50, uniconazole treatment reduced $P_{\mathrm{N}}$ by $34.9 \%$ compared with control, while in Kenfeng 16 , it was by $26.7 \%$ after $4 \mathrm{~d}$ of chilling stress.

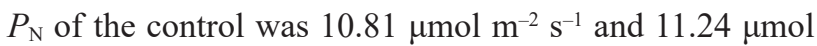
$\mathrm{m}^{-2} \mathrm{~s}^{-1}$, respectively (Fig. $2 A$ ). In this study, photosynthesis recovery proceeded very slowly. In chilling-sensitive Hefeng 50, chilling stress caused a 9.5\% decrease in $P_{\mathrm{N}}$, while in Kenfeng 16 , it was $16.1 \%$ after $4 \mathrm{~d}$ of recovery, compared with the control (Fig. $2 A$ ). However, when chilling-stressed plants were supplemented with uniconazole, $P_{\mathrm{N}}$ was enhanced compared to that under the chilling stress only.

Chl fluorescence parameters: The study of Chl $a$ fluorescence is helpful for identification of the stress-induced damage in photosynthetic apparatus (Erdal 2012). $\mathrm{F}_{\mathrm{v}} / \mathrm{F}_{0}$ (reflecting the potential PSII activity) was affected by chilling stress, manifesting a partial damage of the PSII reaction centers (Table 1). The large decline of $P_{\mathrm{N}}$ followed by the decrease of $F_{v} / F_{m}$ confirmed that PSII is the major target site of chilling stress, particularly during the recovery process (Fig. $3 B$ ). Thus, reduced $P_{\mathrm{N}}$ could result in the accumulation of excessive photon energy and lead to photoinhibition. The ETR of PSII was gradually reduced with the prolongation of low-temperature treatment (Fig. 3A). Chilling stress induced a reduction in the ETR of PSII, which was attributed to both the decrease in the number of open PSII reaction centers and the efficiency of 


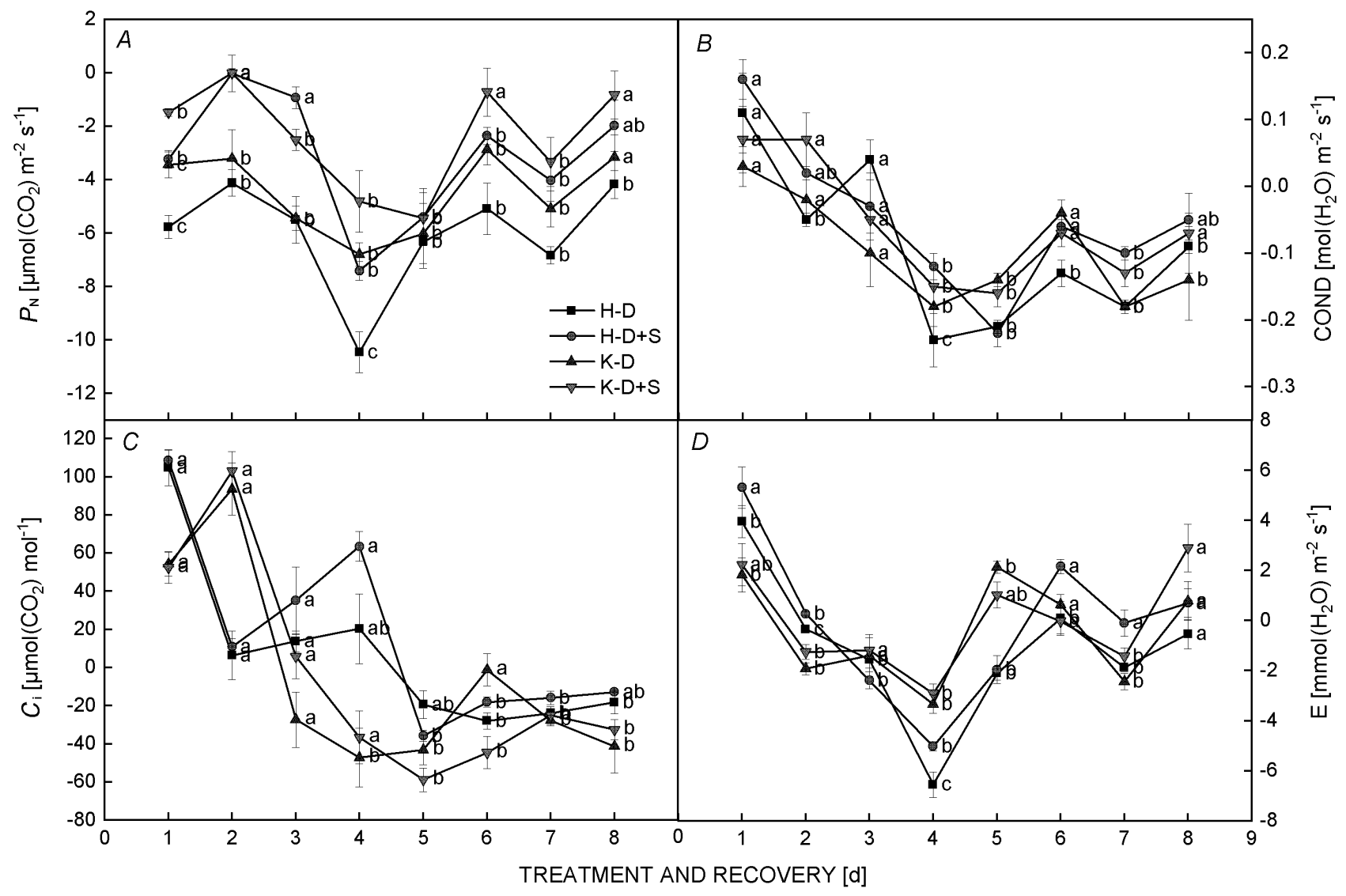

Fig. 2. Effect of uniconazole on net photosynthetic rate $\left(P_{\mathrm{N}}\right)(A)$, stomatal conductance $\left(g_{\mathrm{s}}\right)(B)$, intercellular $\mathrm{CO}_{2}$ concentration $\left(C_{\mathrm{i}}\right)$ $(C)$, and transpiration rate $(E)(D)$ in soybean leaves. From day 1 to day 4 , the plants were under chilling stress, and from day 5 to day 8 , the plants returned to their natural environment (recovery period). Data (means $\pm \mathrm{SE}, n=4$ ) are the difference between treatments. Different letters above horizontal lines indicate significant differences between treatments. D - chilling stress, D $+\mathrm{S}-\mathrm{chilling}$ stress + uniconazole, $\mathrm{H}$ - Hefeng 50, K - Kenfeng 16.

Table 1. Effects of uniconazole on $\mathrm{F}_{\mathrm{v}} / \mathrm{F}_{0}$ in soybean leaves exposed to chilling stress and after recovery to natural environment. Data in the table are the differences between treatment and control. All data are means \pm SE of four repetitions $(n=4)$. Different letters within the same column represent significant differences $(P<0.05)$. D - chilling stress, $\mathrm{D}+\mathrm{S}-$ chilling stress + uniconazole, $\mathrm{H}-\mathrm{Hefeng} 50$, $\mathrm{K}$ - Kenfeng 16.

\begin{tabular}{llllll}
\hline Treatment & $\begin{array}{l}\text { Time of treatment } \\
\text { [d] }\end{array}$ & H-D & H-D $+S$ & K-D & K-D $+S$ \\
\hline Chilling stress & 1 & & & & \\
& 2 & $-0.85 \pm 0.13^{\mathrm{b}}$ & $-0.04 \pm 0.13^{\mathrm{a}}$ & $-0.97 \pm 0.04^{\mathrm{c}}$ & $-0.36 \pm 0.08^{\mathrm{b}}$ \\
& 3 & $-0.99 \pm 0.03^{\mathrm{c}}$ & $-0.53 \pm 0.13^{\mathrm{b}}$ & $-1.10 \pm 0.02^{\mathrm{c}}$ & $-0.70 \pm 0.05^{\mathrm{b}}$ \\
& 4 & $-0.43 \pm 0.01^{\mathrm{b}}$ & $-0.13 \pm 0.06^{\mathrm{a}}$ & $-1.11 \pm 0.07^{\mathrm{c}}$ & $-0.94 \pm 0.05^{\mathrm{b}}$ \\
Recovery & 1 & $-1.11 \pm 0.05^{\mathrm{b}}$ & $-0.75 \pm 0.34^{\mathrm{b}}$ & $-0.89 \pm 0.07^{\mathrm{c}}$ & $-0.42 \pm 0.08^{\mathrm{b}}$ \\
& 2 & $-1.34 \pm 0.08^{\mathrm{c}}$ & $-0.23 \pm 0.01^{\mathrm{b}}$ & $-1.39 \pm 0.08^{\mathrm{c}}$ & $-0.47 \pm 0.03^{\mathrm{b}}$ \\
& 3 & $-1.18 \pm 0.08^{\mathrm{c}}$ & $-0.39 \pm 0.02^{\mathrm{b}}$ & $-1.09 \pm 0.08^{\mathrm{b}}$ & $-0.29 \pm 0.02^{\mathrm{a}}$ \\
& 4 & $-0.36 \pm 0.01^{\mathrm{b}}$ & $-0.03 \pm 0.01^{\mathrm{a}}$ & $-0.33 \pm 0.01^{\mathrm{c}}$ & $-0.28 \pm 0.01^{\mathrm{b}}$ \\
& 4 & $-0.39 \pm 0.04^{\mathrm{b}}$ & $-0.01 \pm 0.01^{\mathrm{a}}$ & $-0.51 \pm 0.02^{\mathrm{b}}$ & $-0.11 \pm 0.03^{\mathrm{a}}$ \\
\hline
\end{tabular}

energy capture by these open centers.

Reactive oxygen species (ROS): Leaves were soaked in $\mathrm{DAB}$ and NBT solution to localize the spots of $\mathrm{O}_{2}^{-}$and $\mathrm{H}_{2} \mathrm{O}_{2}$ at the subcellular level in soybean plants affected by chilling stress. A significant increase of deep blue spots and dark brown patches indicated the accumulation of $\mathrm{O}_{2}{ }^{\circ}$ and $\mathrm{H}_{2} \mathrm{O}_{2}$ in the leaves of soybean plants under chilling stress. However, uniconazole addition reduced the spots of $\mathrm{O}_{2}^{--}$and $\mathrm{H}_{2} \mathrm{O}_{2}$ under chilling stress (Fig. 4).

Our data confirmed that chilling stress induced dramatic accumulation of $\mathrm{O}_{2}{ }^{-}$and malondialdehyde (MDA, indicator 


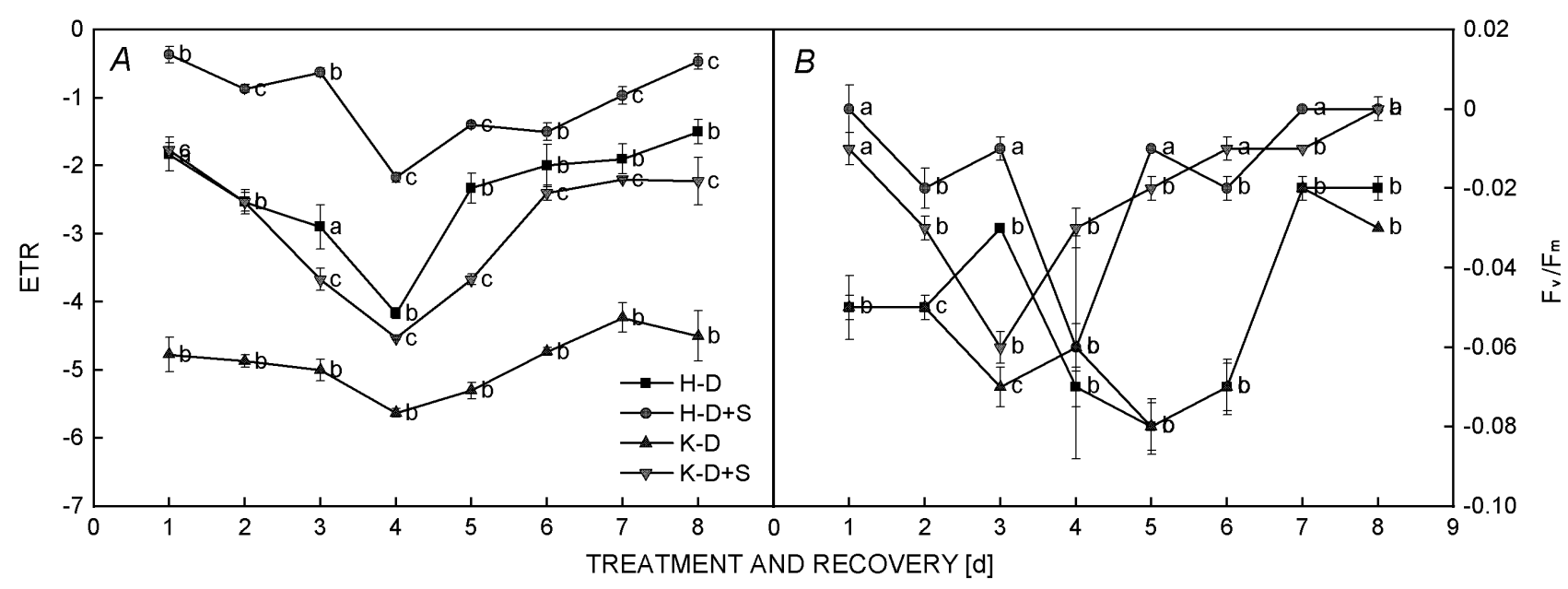

Fig. 3. Effect of uniconazole on electron transport rate (ETR) $(A)$ and maximum photochemical efficiency of PSII $\left(\mathrm{F}_{\mathrm{v}} / \mathrm{F}_{\mathrm{m}}\right)(B)$ in soybean leaves. From day 1 to day 4 , the plants were under chilling stress, and from day 5 to day 8 , the plants returned to their natural environment (recovery period). Data (means $\pm \mathrm{SE}, n=4$ ) are the difference between treatments. Different letters above horizontal lines indicate significant differences between treatments. D - chilling stress, D + S - chilling stress + uniconazole, H - Hefeng 50, K Kenfeng 16.

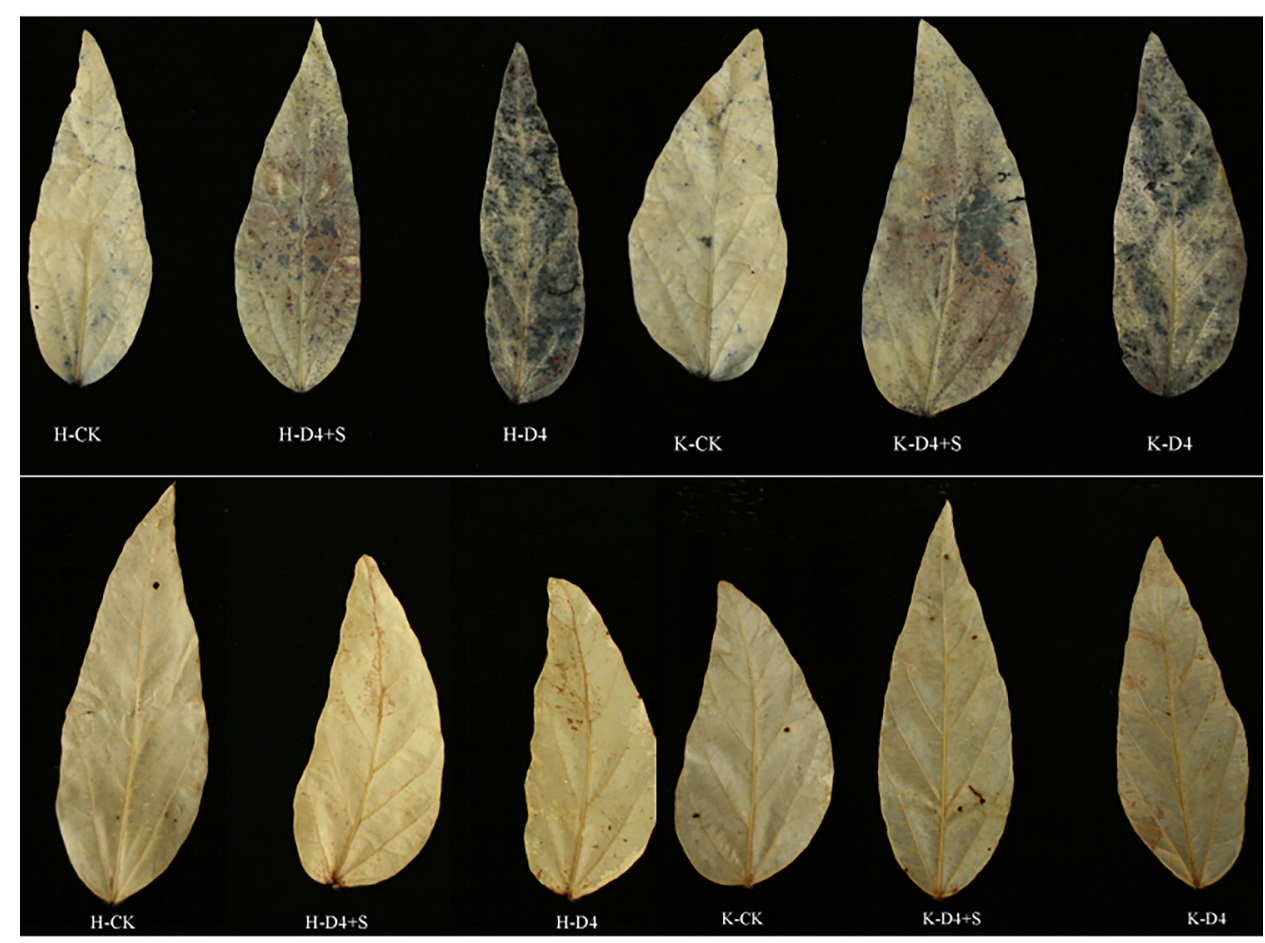

Fig. 4. Histochemical localization of $\mathrm{O}_{2}{ }^{-}$(upper row) and $\mathrm{H}_{2} \mathrm{O}_{2}$ (lower row) in soybean leaves. $\mathrm{K}, \mathrm{H}$, D4, and D4 + $\mathrm{S}$ indicate Kenfeng 16, Hefeng 50, chilling stress for $4 \mathrm{~d}$ and chilling stress + uniconazole for $4 \mathrm{~d}$, respectively. $\mathrm{CK}$ - plants were placed under natural environments.

of lipid peroxidation) in both soybean varieties (Fig. 5). The above contents reached their maximum value when plants were exposed to chilling stress for $4 \mathrm{~d}$. However, the rate of $\mathrm{O}_{2}^{--}$was higher in chilling-sensitive Hefeng 50 as compared to chilling-tolerant Kenfeng 16. Exogenous application of uniconazole significantly reduced the $\mathrm{O}_{2}{ }^{-}$ and MDA contents in both varieties. Our results confirmed that the uniconazole treatment could effectively alleviate the accumulation of ROS in soybean leaves and improve the tolerance to chilling stress.

Accumulation of $\mathrm{O}_{2}^{--}$and MDA gradually decreased with the prolonged recovery time. In Hefeng 50, uniconazole treatment caused 18.0 and $4.0 \%$ decrease in the $\mathrm{O}_{2}{ }^{--}$content, while in Kenfeng 16, it was 28.0 and $11.0 \%$ at 5 and $8 \mathrm{~d}$, respectively, compared with the control (Fig. 5). Moreover, in Hefeng 50 and Kenfeng 16, the uniconazole treatment obviously decreased the MDA content during the recovery process, compared to chilling-treated plants 


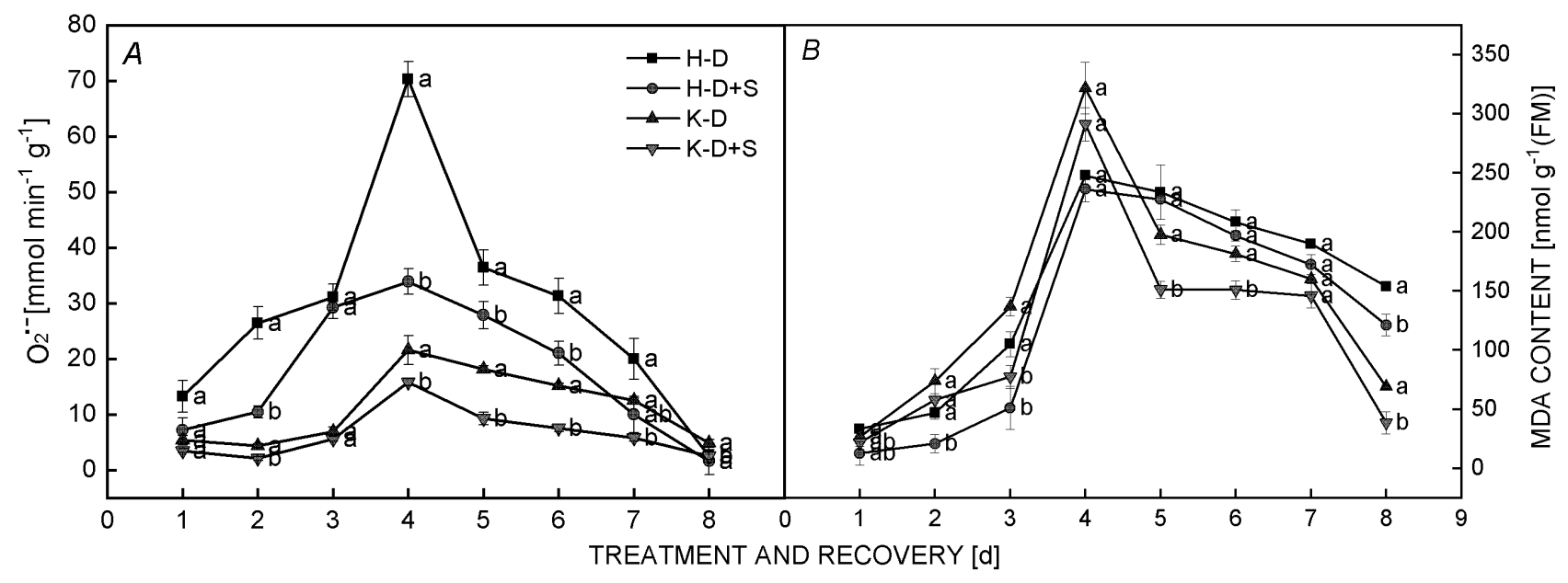

Fig. 5. Effects of uniconazole on superoxide anion $\left(\mathrm{O}_{2}{ }^{-}\right)(A)$ and lipid peroxidation (expressed as malondialdehyde content) $(B)$ in soybean leaves. From day 1 to day 4 , the plants were under chilling stress, and from day 5 to day 8 , the plants returned to their natural environment (recovery period). Data (means $\pm \mathrm{SE}, n=4$ ) are the difference between treatments. Different letters above horizontal lines indicate significant differences between treatments. D - chilling stress, D + S - chilling stress + uniconazole, H - Hefeng 50, K Kenfeng 16.

(Fig. 5). In short, the plants supplemented with uniconazole could maintain lower $\mathrm{O}_{2}^{--}$and MDA content compared to the plants exposed to chilling stress without supplementation during low-temperature treatment and recovery process (Fig. 5). Uniconazole treatments in chilling-stressed plants alleviated the toxic effect of $\mathrm{O}_{2}{ }^{-}$ and MDA but the values were still lower than that of the control during chilling stress and recovery periods.

Nonenzymatic antioxidants: The contents of GSH, GSSG, and GSH + GSSG dramatically increased during lowtemperature stress (compared with the control), which was similar to trends of changes in AsA, DHA, and AsA + DHA contents (Fig. 6). Exogenous uniconazole pretreatment significantly increased these parameters in chilling-stressed plants, compared to the plants exposed to chilling stress only. Leaf contents of GSH, GSSG, and $\mathrm{GSH}+\mathrm{GSSG}$ showed opposite trends when recovering in the natural environment. In chilling-sensitive Hefeng 50, chilling stress caused increases in GSH, GSSG, and $\mathrm{GSH}+\mathrm{GSSG}$ contents, which were 5.1, 0.2, and 2.7\%, respectively, higher than that of the control when plants went back to their natural environment for $4 \mathrm{~d}$ (Fig. $6 A-C$ ). Meanwhile, in chilling-tolerant Kenfeng 16, chilling stress caused increases in GSH, GSSG, and GSH + GSSG contents, which were 2.4, 2.3, and 2.37\% higher, respectively, than that of the control for $4 \mathrm{~d}$ (Fig. 6A-C). The plants supplemented with exogenous uniconazole further increased their GSH, GSSG and GSH + GSSG contents when plants recovered under natural environment.

Leaf contents of AsA + DHA, AsA, and DHA also showed opposite trends when they recovered under the natural environment. In chilling-sensitive Hefeng 50, chilling stress caused a marked increase in AsA + DHA, AsA, and DHA contents which were 39.3, 57.5, and 23.5\% higher, respectively, than that of the control when plants recovered under the natural environment for $4 \mathrm{~d}$ compared with the control (Fig. $6 E-G$ ). However, in chilling-tolerant Kenfeng 16, chilling stress caused a marked increase in AsA + DHA, AsA, and DHA contents, which were 6.8, 3.3 , and $9.3 \%$ higher, respectively, than that of the control when plants recovered under natural environment for $4 \mathrm{~d}$ compared with the control (Fig. $6 E-G$ ). When plants returned back to natural conditions, exogenous uniconazole pretreatment could effectively delay the reduction of AsA + DHA, AsA, and DHA contents. The content of AsA + GSH was increased during the low temperature treatment and then declined during the recovery process. This pattern was similar but slightly lower in the uniconazole-treated plants (Fig. 6H).

Enzymatic antioxidants under chilling stress and recovery: CAT, $\mathrm{POD}, \mathrm{APX}$, and GR are the protective enzymes of the ROS scavenging system in plants. Under chilling stress, the activity of CAT dramatically decreased in Hefeng 50 and Kenfeng 16. In both Hefeng 50 and Kenfeng 16, the activity of CAT was 79.5 and $45.9 \%$ lower, respectively, than that of the control after $4 \mathrm{~d}$ of low temperature treatment. The uniconazole treatment under chilling stress maintained higher CAT activities, compared to chilling stress alone (Fig. 7A). After 1-4 d of low temperature stress, POD activity was sharply enhanced in both soybean varieties, compared with control, whereas in Kenfeng 16, POD activity was higher than that of Hefeng 50. Further, POD activity increased in uniconazole-pretreated, chilling-stressed plants, compared with plants under chilling stress alone (Fig. $7 B$ ). In Hefeng 50 and Kenfeng 16, the activity of APX was 128.9 and $71.4 \%$ higher, respectively, than that of the control after low temperature stress for $4 \mathrm{~d}$. The uniconazole treatment under chilling stress maintained higher APX activities, compared to chilling stress alone, whereas in chillingtolerant Kenfeng 16, the activity was lower than that of Hefeng 50 (Fig. 7C). The treatment by uniconazole 


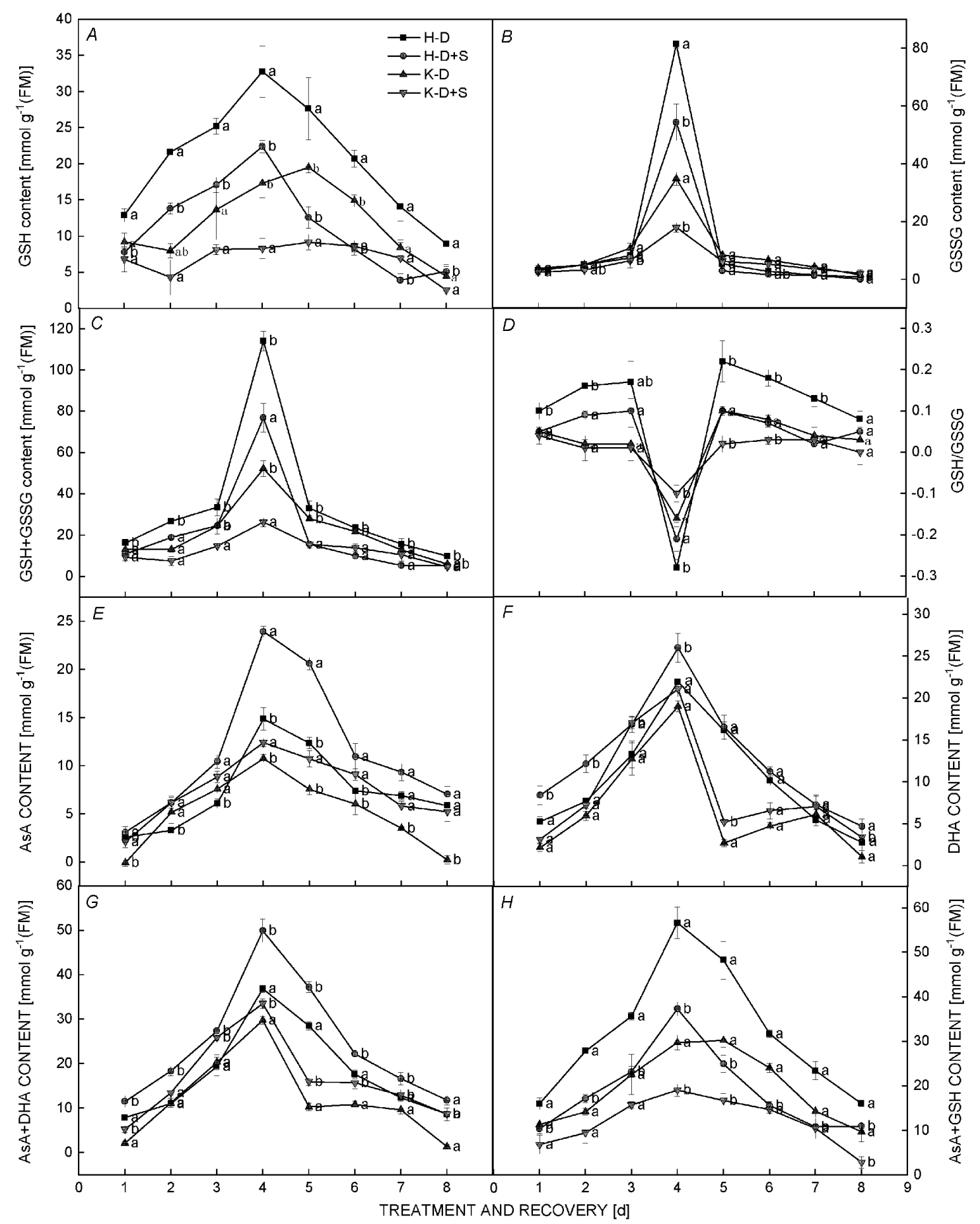

Fig. 6. Effects of uniconazole on the content of nonenzymatic antioxidants in soybean leaves. $(A)$ reduced glutathione $(\mathrm{GSH}),(B)$ oxidized glutathione (GSSG), $(C) \mathrm{GSH}+\mathrm{GSSG},(D) \mathrm{GSH} / \mathrm{GSSG},(E)$ ascorbate (AsA), $(F)$ dehydroascorbate (DHA), $(G)$ AsA + DHA, and $(H)$ AsA + GSH. From day 1 to day 4, the plants were under chilling stress, and from day 5 to day 8 , the plants returned to their natural environment (recovery period). Data (means $\pm \mathrm{SE}, n=4$ ) are the difference between treatments. Different letters above horizontal lines indicate significant differences between treatments. D - chilling stress, D $+\mathrm{S}-$ chilling stress + uniconazole, $\mathrm{H}-\mathrm{Hefeng}$ $50, \mathrm{~K}$ - Kenfeng 16.

under chilling stress increased APX activities in Hefeng 50 by $91.9,66.7,11.6$, and $0.2 \%$, respectively, during the plant recovery to natural environment for $1-4 \mathrm{~d}$, while in Kenfeng 16, it was by 53.9, 37.3, 13.9, and
$11.2 \%$, respectively. The significant enhancement in GR activity was observed under chilling stress. Soybean plants pretreated with uniconazole showed higher GR activity compared to chilling stress-treated plants alone (Fig. 7D). 


\section{Discussion}

Chl and Car are critical for photosynthesis; they allow plant to absorb, transmit, and transform light energy used to provide energy and synthesize photosynthetic products for plant growth and development (Erdal 2012). Kreslavski et al. (2012) reported that chilling stress lead to a decrease in the Chl content. Chl synthesis was inhibited because of pigment synthase activity decreased; and chloroplast structure was damaged. In our experiment, chilling stress caused the reduction in Chl $a$, Chl $b$, Chl $(a+b)$, and Car content. In Kenfeng 16 , the Chl was slightly higher than that of Hefeng 50 which was due to its better tolerance. Previous studies have revealed that $\mathrm{Chl}$ could be bleached under chilling stress, and foliage spray PGRs could improve the Chl content in leaves under low-temperature treatment, which was consistent with the results of this study (Balestrasse et al. 2010, Manafi et al. 2015). The contents of Chl and Car increased when the plants subjected to $15^{\circ} \mathrm{C}$ stress were transferred to their natural environment. The rate of enhancement was higher after the uniconazole treatment.

Damage to membrane components and proteins in thylakoid membrane is commonly the first visible ultrastructural symptom of chilling stress. Therefore, the absorption and transmission of light energy are further affected, which results in a decrease in photosynthetic rate (Allen and Ort 2001). This may be due to chloroplast structure damage and the lower Chl content. In our study, $P_{\mathrm{N}}$ and $g_{\mathrm{s}}$ of the two cultivars significantly decreased under chilling stress, while $C_{\mathrm{i}}$ significantly increased in both soybean varieties. However, the reduction was higher in the chilling-sensitive Hefeng 50 (Fig. 2). It indicated that chilling stress-induced $P_{\mathrm{N}}$ decrease occurred mainly due to nonstomatal limitations. The changes in plant physiological activities and morphological characteristics caused by uniconazole were closely related to alterations in hormone contents in leaves following treatment (Leul and Zhou 1998). Uniconazole was used as a plant growth retarder, which affected the endogenous hormonal balance in leaves after plants were exposed to abiotic stress. Under abiotic stress, uniconazole pretreatment could enhance the ability of chloroplast to absorb and utilize light energy, and alleviate the chloroplast degradation, which improves the ability of plants to resist abiotic stress (Leul and Zhou 1998, Zhang et al. 2007, Duan et al. 2008, Al-Rumaih and Al-Rumaih 2015). Uniconazole treatment significantly increased $P_{\mathrm{N}}, g_{\mathrm{s}}$, and $E$ in soybean leaves under chilling stress compared to chilling treatment alone. The present results indicated that the effect of uniconazole on the photosynthetic characteristics of soybean plants under chilling stress was consistent with that of Zhang et al.

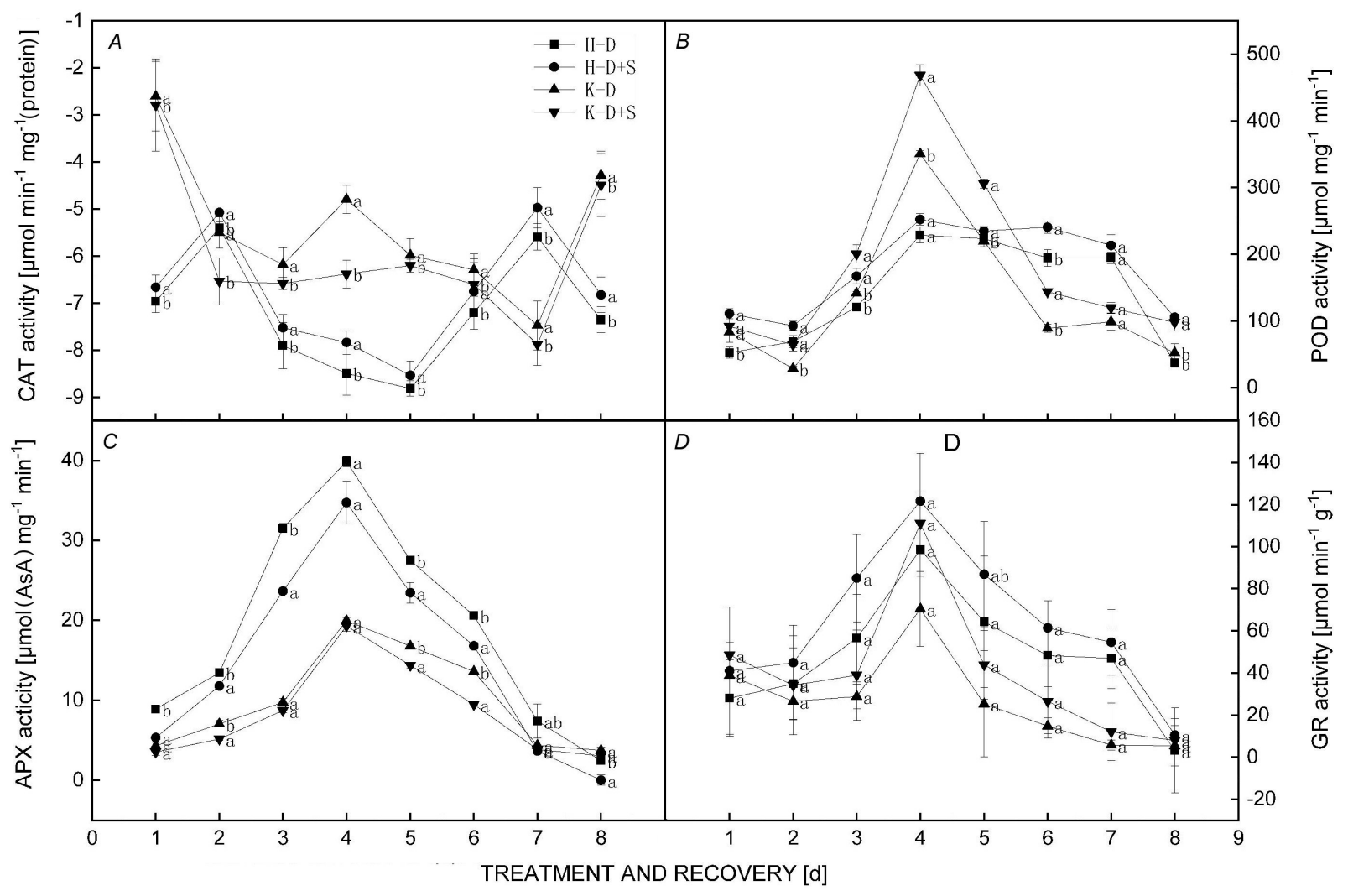

Fig. 7. Effect of uniconazole on the activity of antioxidant enzymes in soybean leaves. $(A)$ catalase $(\mathrm{CAT}),(B)$ peroxidase (POD), $(C)$ ascorbate peroxidase (APX), and $(D)$ glutathione reductase (GR). From day 1 to day 4 , the plants were under chilling stress, and from day 5 to day 8 , the plants returned to their natural environment (recovery period). Data (means $\pm \mathrm{SE}, n=4$ ) are the difference between treatments. Different letters above horizontal lines indicate significant differences between treatments. D - chilling stress, D + S chilling stress + uniconazole, $\mathrm{H}$ - Hefeng 50, $\mathrm{K}$ - Kenfeng 16. 
(2007). However, the photosynthetic parameters of the plants showed the opposite trend during recovery (Fig. 2). When the plants were transferred to their natural environment, the recovery of $P_{\mathrm{N}}$ occurred more quickly after the uniconazole treatment compared to chilling stress only. In chilling-sensitive Hefeng 50 and chillingtolerant Kenfeng 16 , the $P_{\mathrm{N}}$ decreased by 9.5 and $4.2 \%$, respectively, when the plants subjected to $15^{\circ} \mathrm{C}$ stress were transferred to natural environment for $4 \mathrm{~d}$.

Compared to the gas-exchange parameters, Chl fluorescence parameters can directly reflect the absorption and utilization of light energy in PSII, which can assist to analyze the location and extent of photosynthetic organ damage by stress (Demmig and Björkman 1987, Aro et al. 1993, Erdal 2012). Chilling stress induced a decrease of $F_{v} / F_{m}$, indicating that chilling stress can cause partial inactivation or injury to PSII (Demmig and Björkman 1987). Photosynthetic organs were damaged and the photosynthetic electron transport process was blocked which ultimately resulted in a decrease of ETR (Ögren 1991). The results revealed that the fluorescence parameters of the two varieties of soybean showed the same trend. Under chilling stress, $\mathrm{F}_{\mathrm{v}} / \mathrm{F}_{\mathrm{m}}$ and ETR in soybean leaves significantly decreased, and the reduction was higher in the chilling-sensitive Hefeng 50 (Table 1, Fig. 3). Under chilling stress, uniconazole pretreatment could further decrease $F_{v} / F_{m}$ and ETR, which indicates that the mechanism of plant thermal dissipation was inefficient. Chilling stress caused irreversible inactivation or destruction of PSII reaction centers. Under chilling stress, exogenous uniconazole treatment significantly increased $P_{\mathrm{N}}, g_{\mathrm{s}}, E, \mathrm{~F}_{\mathrm{v}} / \mathrm{F}_{\mathrm{m}}$, and ETR, avoided excessive light damage, maintained high PSII photochemical activity, and relieved the inhibition of soybean growth. However, the photosynthetic parameters of the plant showed the opposite trend during recovery days (Table 1, Fig. 3).

Chilling stress is a major factor limiting the growth, development, survival, and yield of many temperaturesensitive plants (Allen and Ort 2001). Chilling stress accelerates the production of ROS and induction of oxidative stress, which eventually results in cell death (Gill and Tuteia 2010, Kreslavski et al. 2012, Nahar et al. 2015). In the present study, histochemical staining localized $\mathrm{O}_{2}{ }^{-}$and $\mathrm{H}_{2} \mathrm{O}_{2}$ at the tissue level in soybean leaves. Chilling stress induced the accumulation of $\mathrm{O}_{2}{ }^{-}$ and $\mathrm{H}_{2} \mathrm{O}_{2}$ (Fig. 4). $\mathrm{O}_{2}^{--}$is a toxic compound which is injurious to the cell and excessive accumulation of $\mathrm{O}_{2}{ }^{-}$is one of the indicators of oxidative stress (Gill and Tuteja 2010). Lipid peroxidation is a better known indicator for determining the extent of oxidative stress. In our study, both $\mathrm{O}_{2}{ }^{-}$and MDA were found to be increased under chilling stress which was in agreement with several previous reports (Liu et al. 2009, 2011, 2012; Balestrasse et al. 2010, Erdal 2012, Nahar et al. 2015). On the contrary, chilling-treated plants supplemented with exogenous uniconazole showed lower $\mathrm{O}_{2}{ }^{--}$and MDA contents (Figs. $4,5)$ which was due to their more active nonenzymatic and enzymatic antioxidant defense system. Exogenous uniconazole-induced upregulation of nonenzymatic and enzymatic antioxidant defense and concomitant decrease in $\mathrm{O}_{2}{ }^{-}$and MDA contents were observed in many plant species including soybean (Balestrasse et al. 2010). This is consistent with the study reported by Zhang et al. (2007) in soybean under water deficit stress. Chucheep et al. (2005) reported that exogenous uniconazole increased a tolerance of mung bean seedlings to chilling stress. Therefore, it is clear that uniconazole can alleviate membrane damage caused by overaccumulation of ROS. Other researches have confirmed that pretreatment with uniconazole can decrease ROS in plants under different abiotic stresses (Leul and Zhou 1998, Qiu et al. 2005, Zhang et al. 2007, Duan et al. 2008).

Plants in a long process of evolution have formed a variety of mechanisms to resist oxidative stress and to remove excess ROS, so that oxygen free radicals maintain at a low concentration (Gill and Tuteja 2010, Nahar et al. 2015). AsA and GSH contents are important parameters to measure the ability of plants to resist low temperature stress. Two molecules of AsA as substrate are utilized by APX to scavenge $\mathrm{H}_{2} \mathrm{O}_{2}$ to water, and with the concomitant generation of MDHA, which can disproportionate into DHA and AsA. NADPH acts as electron donor and the reaction is catalyzed by ferredoxin in a water-water cycle or MDHAR (Hasanuzzaman et al. 2012). Two molecules of GSH are utilized by DHAR to reduce DHA to AsA, and during this reaction, GSSG is generated (Gill and Tuteja 2010). Previous studies have shown that exogenous PGRs increased the content of AsA and GSH under low temperature stress, reduced the oxidative damage in plant cells, and improved the tolerance to stress (Liu et al. 2009, 2011, Balestrasse et al. 2010, Manafi et al. 2015, Nahar et al. 2015, Zhao et al. 2016). Our results revealed that chilling stress led to the increase in AsA, DHA, and total AsA contents in both soybean varieties (Fig. 6E-G). Moreover, uniconazole treatment dramatically increased AsA, DHA, and total AsA contents, but the increase of AsA content was higher than that of DHA. This result indicated uniconazole could improve the tolerance of soybean plants to low temperature mainly by increasing the content of AsA as an antioxidant. GSH acts as an antioxidant to scavenge different ROS by preventing the oxidation of protein thiol groups and eventually preventing denaturation of proteins (Nahar et al. 2015). Nahar et al. (2015) reported that chilling stress slightly increased GSH content and reduced GSH/GSSG ratio, while pretreatment with spermidine increased GSH content and GSH/GSSH ratio, compared to seedlings under chilling stress alone. It was found that GSH, GSSG, GSH + GSSG contents and GSH/GSSG ratio of both varieties increased. The similar results were observed after the uniconazole pretreatment of both soybean cultivars. The enhancement of the GSH/GSSG ratio was beneficial to maintain a balance state of AsAGSH cycle and scavenging ROS (Fig. 6). In addition, APX activity was enhanced in both soybean varieties subjected to chilling stress; exogenous uniconazole increased the activity further which indicated the $\mathrm{H}_{2} \mathrm{O}_{2}$ scavenging role of uniconazole (Fig. $7 C$ ). In short, exogenous uniconazole increased the activity of APX and the contents of AsA and $\mathrm{GSH}$, which indicated that uniconazole may promote the AsA-GSH cycle under chilling stress. 
SOD, POD, and CAT are ROS scavengers. The main function of SOD is to clear the generation of $\mathrm{H}_{2} \mathrm{O}_{2}$ and oxygen molecules, and POD and CAT can remove $\mathrm{H}_{2} \mathrm{O}_{2}$ in cells and prevent $\mathrm{H}_{2} \mathrm{O}_{2}$ and $\mathrm{O}_{2}{ }^{-}$interaction, so as to maintain the balance of active oxygen metabolism (Gill and Tuteja 2010, Hasanuzzaman et al. 2012). Previous studies have shown that the activities of SOD, POD, and CAT in different plants are different under low temperature stress. Upadhyaya et al. (1990) elucidated that uniconazole-induced stress tolerance is due to enhanced antioxidant activity which reduced stress-related oxidative damage to cell membranes. Manafi et al. (2015) reported that in soybean seedlings treated by $10^{\circ} \mathrm{C}$ temperature stress, SOD and POD activity increased. Nahar et al. (2015) found that CAT activity decreased under low temperature stress. In this study, it was found that chillingstress treatment increased POD activity and no significant difference of SOD activity was found (the data not shown) in soybean leaves (Fig. 7A). Zhang et al. (2007) found that uniconazole could increase the activity of SOD and POD under water deficit stress, and decrease the content of MDA. Foliar sprays of uniconazole under waterlogging stress significantly increased the activities of POD and CAT enzymes and significantly reduced the MDA content at the seedling and flowering stage, while there was no significant difference in SOD activity between uniconazole and waterlogging stress at both stages (Leul and Zhou 1998). The results of this study also showed that uniconazole treatment significantly improved the activity of POD and CAT in the leaves of soybean plants (Fig. $7 A, B$ ), and reduced the degree of plasma membrane peroxidation $\left(\mathrm{O}_{2}{ }^{-}\right.$and MDA content) and maintained the integrity of cell membrane. In both soybean varieties from our experiment, POD and CAT activities obviously increased under low temperature stress, higher activities were observed in chilling-sensitive Hefeng 50. Exogenous uniconazole resulted in further enhancement of the above indicators.

However, the ROS, nonenzymatic, and enzymatic antioxidants showed the opposite trend during recovery days (Figs. 5, 6). When the plants were transferred to natural environment, the recovery of above indicators occurred more quickly after the uniconazole treatment compared to chilling stress only. In chilling-tolerant Kenfeng 16, the above indicators mostly reached normal levels when the plants were transferred to natural environment for 4 d. In summary, we infer that uniconazole could improve the low temperature tolerance of crops, because the uniconazole treatment could reduce the production of ROS and promote nonenzymatic and enzymatic antioxidant defense system to eliminate excessive ROS in plants under low temperature stress. When the plants were transferred to natural environment, the recovery of photosynthetic pigment, gas-exchange parameters, ROS, nonenzymatic and enzymatic antioxidants occurred more quickly and mostly reached normal levels.

Conclusion: The results of our study indicated that chilling stress decreased photosynthetic pigments and $P_{\mathrm{N}}$, and increased the $\mathrm{O}_{2}{ }^{-}$and MDA content in two soybean varieties. Considering the above results, we conclude that foliar application of $50 \mathrm{mg}$ (uniconazole) $\mathrm{L}^{-1}$ to plants together with chilling stress improved the growth, photosynthesis, and ROS metabolism (ROS production and removal) compared to plants treated with chilling stress alone. In all cases, Kenfeng 16 performed better than Hefeng 50 under low temperature stress. Thus, we suggest that the application of uniconazole has practical importance in agricultural systems.

\section{References}

Allen D.J., Ort D.R.: Impacts of chilling temperatures on photosynthesis in warm-climate plants. - Trends Plant Sci. 6: 36-42, 2001.

Al-Rumaih M.M., Al-Rumaih M.M.: Physiological response of two species of datura to uniconazole and salt stress. - J. Food Agric. Environ. 46: 663-668, 2015.

Arnon D.T.: Copper enzymes in isolated chloroplasts. Polyphenoloxidase in Beta vulgaris. - Plant Physiol. 24: 1-15, 1949.

Aro E.M., Virgin I., Andersson B.: Photoinhibition of photosystem II. Inactivation, protein damage and turnover. Biochim. Biophys. Acta 1143: 113-134, 1993.

Balestrasse K.B., Tomaro M.L., Batlle A., Noriega, G.O.: The role of 5-aminolevulinic acid in the response to cold stress in soybean plants. - Phytochemistry 71: 2038-2045, 2010.

Cakmak I., Marschner H.: Magnesium deficiency and high light intensity enhance activities of superoxide dismutase, ascorbate peroxidase, and glutathione reductase in bean leaves. - Plant Physiol. 98: 1222-1227, 1992.

Chen F., Wang F., Wu F. et al.: Modulation of exogenous glutathione in antioxidant defense system against Cd stress in the two barley genotypes differing in Cd tolerance. - Plant Physiol. Bioch. 48: 663-672, 2010.

Chucheep K., Kanlayanarat S., Matsuo T.: Analogous effect of preheating on chilling sensitivity of mung bean seedlings and membrane viscosity to effects of ABA and uniconazole treatments. - J. Food Agric. Environ. 3: 110-116, 2005.

Demmig B., Björkman O.: Comparison of the effect of excessive light on chlorophyll fluorescence $(77 \mathrm{~K})$ and photon yield of $\mathrm{O}_{2}$ evolution in leaves of higher plants. - Planta 171: 171-184, 1987.

Dhindsa R.S., Plumb-Dhindsa P., Thorpe T.A.: Leaf senescence correlated with increased levels of membrane permeability and lipid peroxidation, and decreased levels of superoxide dismutase and catalase. - J. Exp. Bot. 32: 93-101, 1981.

Duan L., Guan C., Li J. et al.: Compensative effects of chemical regulation with uniconazole on physiological damages caused by water deficiency during the grain filling stage of wheat. $-\mathrm{J}$. Agron. Crop Sci. 194: 9-14, 2008.

Egli D.B.: Flowering, pod set and reproductive success in soya bean. - J. Agron. Crop Sci. 191: 283-291, 2005.

Erdal S.: Androsterone-induced molecular and physiological changes in maize seedlings in response to chilling stress. Plant Physiol. Bioch. 57: 1-7, 2012.

Esterbauer H., Grill D.: Seasonal variation of glutathione and glutathione reductase in needles of Picea abies. - Plant Physiol. 61: 119-121, 1978.

Fu J., Huang B.: Involvement of antioxidants and lipid peroxidation in the adaptation of two cool-season grasses to localized drought stress. - Environ. Exp. Bot. 45: 105-114, 2001.

Funatsuki H., Matsuba S., Kawaguchi K. et al.: Methods for evaluation of soybean chilling tolerance at the reproductive stage under artificial climatic conditions. - Plant Breeding 123: 558-563, 2004. 
Gill S.S., Tuteja N.: Reactive oxygen species and antioxidant machinery in abiotic stress tolerance in crop plants. - Plant Physiol. Bioch. 48: 909-930, 2010.

Grace S.C., Logan B.A.: Acclimation of foliar antioxidant systems to growth irradiance in three broad-leaved evergreen species. - Plant Physiol. 112: 1631-1640, 1996.

Hall A.E.: Crop Response to Environment. Pp. 248. CRC Press, New York 2000.

Hasanuzzaman M., Hossain M.A., Teixeira da Silva J.A., Fujita M.: Plant response and tolerance to abiotic oxidative stress: Antioxidant defense is a key factor. - In: Venkateswarlu B., Shanker A., Shanker C., Maheswari M. (ed.): Crop Stress and its Management: Perspectives and Strategies. Pp. 261-315. Springer, Dordrecht 2012.

Ikeda T., Ohnishi S., Senda M. et al.: A novel major quantitative trait locus controlling seed development at low temperature in soybean (Glycine max). - Theor. Appl. Genet. 118: 1477$1488,2009$.

He J., Lin L., Ma Q. et al.: Uniconazole (S-3307) strengthens the growth and cadmium accumulation of accumulator plant Malachium aquaticum. - Int. J. Phytoremediat. 19: 348-352, 2017.

Kreslavski V.D., Los D.A., Allakhverdiev S.I., Kuznetsov V.V.: Signaling role of reactive oxygen species in plants under stress. - Russ. J. Plant. Physl+ 59: 141-154, 2012.

Leul M., Zhou W.: Alleviation of waterlogging damage in winter rape by application of uniconazole: Effects on morphological characteristics, hormones and photosynthesis. - Field Crop. Res. 59:121-127, 1998.

Liu Y., Jiang H., Zhao Z., An L.: Abscisic acid is involved in brassinosteroids-induced chilling tolerance in the suspension cultured cells from Chorispora bungeana. - J. Plant Physiol. 168: 853-862, 2011.

Liu Y., Zhao Z., Si J. et al.: Brassinosteroids alleviate chillinginduced oxidative damage by enhancing antioxidant defense system in suspension cultured cells of Chorispora bungeana. - Plant Growth Regul. 59: 207-214, 2009.

Liu Y.F., Qi M.F., Li T.L.: Photosynthesis, photoinhibition, and antioxidant system in tomato leaves stressed by low night temperature and their subsequent recovery. - Plant Sci. 196: 8-17, 2012.

Liu Y.F., Zhang G.X., Qi M.F., Li T.L.: Effects of calcium on photosynthesis, antioxidant system, and chloroplast ultrastructure in tomato leaves under low night temperature stress. - J. Plant Growth Regul. 34: 263-273, 2015.

Manafi E., Modarres Sanavy S.A.M., Aghaalikhani M., Dolatabadian A.: Exogenous 5-aminolevulenic acid promotes antioxidative defence system, photosynthesis and growth in soybean against cold stress. - Not. Sci. Biol. 7: 486-494, 2015.

Nahar K., Hasanuzzaman M., Alam M.M., Fujita M.: Exogenous spermidine alleviates low temperature injury in mung bean (Vigna radiata L.) seedlings by modulating ascorbateglutathione and glyoxalase pathway. - Int. J. Mol. Sci. 16: 30117-30132, 2015.

Nahar K., Hasanuzzaman M., Alam M.M. et al.: Polyamine and nitric oxide crosstalk: antagonistic effects on cadmium toxicity in mung bean plants through upregulating the metal detoxification, antioxidant defense, and methylglyoxal detoxification systems. - Ecotox. Environ. Safe. 126: 245255, 2016.

Ögren E.: Prediction of photoinhibition of photosynthesis from measurements of fluorescence quenching components. Planta 184: 538-544, 1991.

Ohnishi S., Miyoshi T., Shirai S.: Low temperature stress at different flower developmental stages affects pollen development, pollination, and pod set in soybean. - Environ. Exp. Bot. 69: 56-62, 2010.

Polle A., Otter T., Seifert F.: Apoplastic peroxidases and lignification in needles of Norway (Picea abies L.). - Plant Physiol. 106: 53-60, 1994.

Qiu J., Wang R., Yan J., Hu J.: Seed film coating with uniconazole improves rape seedling growth in relation to physiological changes under waterlogging stress. - Plant Growth Regul. 47: 75-81, 2005.

Saito S., Okamoto M., Shinoda S. et al.: A plant growth retardant, uniconazole, is a potent inhibitor of ABA catabolism in Arabidopsis. - Biosci. Biotech. Bioch.70: 1731-1739, 2006.

Savitch L.V., Gray G.R., Huner N.P.A.: Feedback-limited photosynthesis and regulation of sucrose-starch accumulation during cold acclimation and low-temperature stress in a spring and winter wheat. - Planta 201: 18-26, 1997.

Singh S.K., Kakani V.G., Surabhi G.K., Reddy K.R.: Cowpea (Vigna unguiculata [L.] Walp.) genotypes response to multiple abiotic stresses. - J. Photoch. Photobio. B 100: 135146, 2010.

Strauss A.J., Krüger G.H.J., Strasser R.J., Van Heerden P.D.R.: Ranking of dark chilling tolerance in soybean genotypes probed by the chlorophyll $a$ fluorescence transient O-J-I-P. Environ. Exp. Bot. 56: 147-157, 2006.

Takahashi R., Benitez E.R., Funatsuki H., Ohnishi S.: Soybean maturity and pubescence color genes improve chilling tolerance. - Crop Sci. 45: 1387-1393, 2005.

Tian X., Liu Y., Huang Z. et al.: Comparative proteomic analysis of seedling leaves of cold-tolerant and -sensitive spring soybean cultivars. - Mol. Biol. Rep. 42: 581-601, 2015.

Todoroki Y., Kobayashi K., Shirakura M. et al.: Abscinazole-F1, a conformationally restricted analogue of the plant growth retardant uniconazole and an inhibitor of ABA 8'-hydroxylase CYP707A with no growth-retardant effect. - Bioorgan. Med. Chem. 17: 6620-6630, 2009.

Upadhyaya A., Davis T.D., Larsen M.H. et al.: Uniconazoleinduced thermotolerance in soybean seedling root tissue. Physiol. Plantarum 79: 78-84, 1990.

Wan Z., Kothare M.V.: Uniconazole-induced tolerance of rape plants to heat stress in relation to changes in hormonal levels, enzyme activities and lipid peroxidation. - Plant Growth Regul. 27: 99-104, 1999.

Wang A.G., Luo G.H.: Quantitative relation between the reaction of hydroxylamine and superoxide anion radicals in plants. Plant Physiol. Commun. 6: 55-57, 1990.

Wei W., Li Q.T., Chu Y.N. et al.: Melatonin enhances plant growth and abiotic stress tolerance in soybean plants. - J. Exp. Bot. 66: 695-707, 2015.

Yan Y., Wan Y., Liu W. et al.: Influence of seed treatment with uniconazole powder on soybean growth, photosynthesis, dry matter accumulation after flowering and yield in relay strip intercropping system. - Plant Prod. Sci. 18: 295-301, 2015.

Zhang J., Kirkham M.B.: Antioxidant responses to drought in sunflower and sorghum seedlings. - New Phytol. 132: 361373, 1996.

Zhang M., Duan L., Tian X. et al.: Uniconazole-induced tolerance of soybean to water deficit stress in relation to changes in photosynthesis, hormones and antioxidant system. - J. Plant Physiol. 164: 709-717, 2007.

Zhao H., Ye L., Wang Y. et al.: Melatonin increases the chilling tolerance of chloroplast in cucumber seedlings by regulating photosynthetic electron flux and the ascorbate-glutathione cycle. - Front. Plant Sci. 7: 1814, 2016.

(C) The authors. This is an open access article distributed under the terms of the Creative Commons BY-NC-ND Licence. 